\title{
Ventromedial septal lesions in rats reduce stomach erosions produced by inescapable shock
}

\author{
JOHN E. KELSEY \\ Bates College, Lewiston, Maine
}

\begin{abstract}
Exposure to inescapable shock produced fewer and less extensive stomach erosions in rats with ventromedial septal lesions than in the sham-operated controls. This finding, in conjunction with our previous findings that ventromedial septal lesions also reduce several other physiological and behavioral responses to the stress of inescapable shock, indicates that this area of the limbic system is importantly involved in mediating several responses to inescapable shock. It is suggested that, by disrupting the cholinergic septohippocampal system, ventromedial septal lesions may reduce the ability of rats to learn that shocks are inescapable or may reduce the aversiveness of such knowledge.
\end{abstract}

Lesions of the ventromedial septum in rats reduce or eliminate several physiological and behavioral responses to the stress of inescapable shock. For example, these lesions reduce the enhanced secretion of corticosterone (Kelsey, 1975), the loss of body weight, and the analgesia or decreased pain sensitivity produced by exposure to inescapable shocks (Kelsey \& Baker, 1983). In addition to reducing these shortterm responses to inescapable shocks, ventromedial septal lesions also reduce the interfering effects of inescapable shocks on subsequent escape performance (learned helplessness; Kelsey \& Baker, 1983).

The intent of this study was to explore the generality of these findings by determining if ventromedial septal lesions would also reduce another physiological response to inescapable shock-stomach erosions, commonly referred to as stress ulcers. Indicating that these lesions might reduce gastric erosion formation, Brick, Burright, and Donovick (1979) reported that large septal lesions reduced the length of gastric erosions produced by $3 \mathrm{~h}$ of cold restraint. However, Henke (1982) found that large septal lesions did not affect the formation of gastric erosions produced by $24 \mathrm{~h}$ of restraint at room temperature.

\section{METHOD}

\section{Subjects}

The 33 naive, male Sprague-Dawley rats weighed $221-300 \mathrm{~g}$ at the time of surgery. They were housed one to a cage in a colony that was lighted from 7 a.m. to 7 p.m. each day. They had adlib access to food and water except where noted.

\section{Surgery}

The rats were injected ip with $.5 \mathrm{cc}$ of atropine sulfate $(1 \mathrm{mg} / \mathrm{cc})$

Reprint requests should be sent to the author at the Department of Psychology, Bates College, Lewiston, ME 04240.
$10 \mathrm{~min}$ prior to the ip injection of the anesthetic, Equi-Thesin (Jensen-Salsbery; $2.8 \mathrm{cc} / \mathrm{kg}$ ). Electrolytic lesions were made in the ventromedial septum of 19 rats by passing $2 \mathrm{~mA}$ of anodal current for $15 \mathrm{sec}$ between the stereotaxically positioned brain electrode and an indifferent electrode attached to the skin opened by the incision. The brain electrode, which was implanted at an 11deg angle to avoid the midsagittal sinus, was a stainless steel No. 1 insect pin, completely insulated except for the cross section of the flattened tip. Sham operations that were identical except that the electrode was not lowered into the brain were performed on 14 rats.

\section{Apparatus}

Two $20 \times 49 \times 31 \mathrm{~cm}$ shuttleboxes were made of galvanized steel except for the front and tops, which were made of clear Plexiglas. The floor was made of .6-cm-diam stainless steel rods separated by $2 \mathrm{~cm}$ (center to center). Each shuttlebox was housed inside its own ventilated, sound-attenuating shell, which was illuminated by a dim houselight. Speakers located at the top of each shell supplied a masking white noise of $65 \mathrm{~dB}$ SPL.

The two constant current shock sources consisted of 5,000-V ac transformers in series with limiting resistors. The output of one shocker was connected to the two end grids of one shuttlebox, and the output of the second shocker was similarly connected to the end grids of the remaining shuttlebox. A neon (NE-2) bulb was wired between each of the grids in both shuttleboxes, and the steel walls were connected to the center grids. The current in the shuttleboxes was measured across six consecutive grids with no rat on the grid floor and was pulsed at the rate of $1.5 / \mathrm{sec}$ with an on time of $.4 \mathrm{sec}$.

\section{Procedure}

Between 2 and 5 weeks following surgery, the rats were weighed and deprived of food. The sawdust bedding was removed from below their cages to prevent the rats from eating it or any previously spilled food. Twenty-four hours later, the rats were exposed to inescapable shocks in the shuttleboxes during a 1-h session. The procedure for presenting the inescapable shocks was adapted from a procedure that is effective in producing stomach erosions in rats in only $1 \mathrm{~h}$ (Hamilton \& Katske, 1973). Seven seconds of inescapable shocks (1.2 $\mathrm{mA})$ were presented according to a variable-time 60 $\mathrm{sec}$ schedule. Additional inescapable shocks, varying in duration between 3 and $19 \mathrm{sec}$, were presented according to a fixed-time 45$\mathrm{sec}$ schedule. This procedure generated approximately 130 shocks totaling $18.8 \mathrm{~min}$ during the $1-\mathrm{h}$ period. Crossing responses were 
automatically recorded when the rat moved the middle of its body approximately 6.5 grids $(13 \mathrm{~cm})$ across the center grid into the opposite side of the shuttlebox, but these responses had no effect on the shocks. All testing occurred during the day.

Immediately following the 1-h session, the rats were killed with chloroform and the stomach of each was tied off at the esophogeal entrance and removed. Each stomach was inflated with $9 \mathrm{cc}$ of calcium chloride-buffered $10 \%$ formol-saline, tied off at the pyloric sphincter, and submerged in buffered $10 \%$ formol-saline. Approximately 10 min later, the stomach was cut along the greater curvature and gently cleaned with water. With the aid of a dissecting microscope, the mucous was gently scraped from the glandular portion of the stomach with a rounded spatula so that the stomach wall was visible. The stomachs were then placed in buffered $10 \%$ formol-saline and 2-4 weeks later were reexamined. At this time, the length and width of each remaining erosion (defects or breaks in the mucosal wall still containing clotted blood) were measured by a caliper to the nearest $.1 \mathrm{~mm}$ under a dissecting microscope. The area of each erosion was estimated by multiplying the length by the width. Irregularly shaped erosions were assessed by separately measuring the areas of their component parts.

\section{Histology}

Immediately after the stomachs were removed, the rats with septal lesions were perfused intracardially with isotonic saline followed by a $10 \%$ formol-saline solution. Every fifth $40-\mu$-thick frozen section in the area of the lesion was saved, stained with cresyl violet, and examined under a microscope.

\section{RESULTS}

The ventromedial septal lesions of 17 rats were similar to those described by Kelsey and Baker 1983) (see Figure 1). These lesions extensively damaged the medial septal nucleus and the dorsal tip of the diagonal band of Broca. Damage to the lateral septal nuclei was usually small and unilateral. One rat was eliminated from the study because its lesion extended ventrally into the medial preoptic area, and another was eliminated because its lesion was too small.

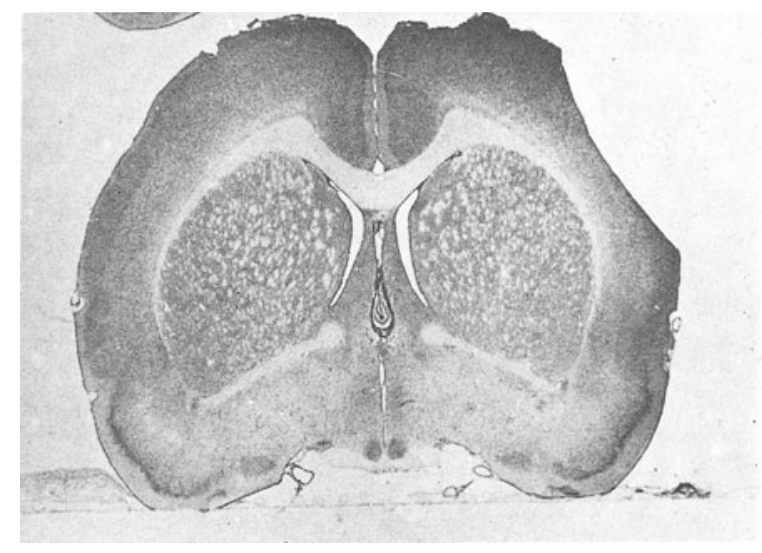

Figure 1. A photomicrograph of a representative ventromedial septal lesion.
The gastric erosions were confined to the acidsecreting glandular portion of the stomach. Because these erosions did not penetrate the muscle wall, they will be referred to as erosions rather than ulcers (cf. Weiss, 1977). During the 1-h exposure to inescapable shock, the rats with ventromedial septal lesions developed fewer $[\mathrm{t}(29)=2.39, \mathrm{p}<.03]$ and less extensive $[t(29)=2.23, p<.04]$ stomach erosions than the sham-operated controls (see Table 1, Section A).

The rats with ventromedial septal lesions also made more crossing responses in the shuttleboxes than the controls [ $\mathrm{t}(29)=5.70, \mathrm{p}<.001$; (see Table 1 , Section A]. Correlations between the number of crossing responses and stomach erosions were not significant for either group $(r=-.10$ and .34 for the control and septal groups, respectively). Although the rats with ventromedial septal lesions tended to weigh less than the controls, this difference was not significant.

A more complete analysis of the gastric erosion data indicated that the rats with ventromedial septal lesions did not comprise a homogeneous group, because the rats with more ventral lesions developed larger gastric erosions than did the rats with more dorsal ventromedial septal lesions (see Table 1, Section B). The five rats with lesions that extended more than $1.2 \mathrm{~mm}$ ventral to the zero plane (Pellegrino \& Cushman, 1967) at their maximal ventral extent developed erosions that were as extensive as those of the controls (cf. Table 1, Section A) and more extensive than those of the 12 rats with more dorsal lesions $[t(15)=2.63, p<.02$, and $t(15)=2.55, p<$ .03 , for number and area, respectively; see Table 1, Section B]. Furthermore, inclusion of the data (24 erosions comprising $5.69 \mathrm{~mm}^{2}$ ) from the rat whose data had been excluded because its lesion extended ventrally into the medial preoptic area enhanced this difference between the subgroups. These two subgroups did not differ in number of crossing responses or body weight (see Table 1, Section B). Because the lesions of these two subgroups did not differ in their dorsal extent, these data suggest that neurons in the most ventral septum and medial preoptic area have a function in the mediation of gastric erosions that is opposite to that of the more dorsal ventromedial septal fibers.

\section{DISCUSSION}

This study demonstrated that the number and extent of stomach erosions produced by exposure to inescapable shock in rats were reduced by ventromedial septal lesions. These data are, thus, consistent with the data demonstrating that several other short-term and long-term effects of exposure to inescapable shock, including enhanced corticosterone secretion, loss of body weight, analgesia or decreased pain sen- 
Table 1

Effects of Ventromedial Septal Lesions on Stomach Erosions, Shuttlebox Crossing Responses, and Body Weight

\begin{tabular}{|c|c|c|c|c|c|c|c|c|c|}
\hline \multirow[b]{2}{*}{ Group } & \multirow[b]{2}{*}{$\mathrm{N}$} & \multicolumn{2}{|c|}{$\begin{array}{l}\text { Number of } \\
\text { Erosions }\end{array}$} & \multicolumn{2}{|c|}{$\begin{array}{c}\text { Area of } \\
\text { Erosions }\left(\mathrm{mm}^{2}\right)\end{array}$} & \multicolumn{2}{|c|}{$\begin{array}{l}\text { Crossing } \\
\text { Responses }\end{array}$} & \multicolumn{2}{|c|}{ Body Weight (g) } \\
\hline & & Mean & SEM & Mean & SEM & Mean & SEM & Mean & SEM \\
\hline \multicolumn{10}{|c|}{ A. Controls vs. Lesions } \\
\hline Controls & 14 & 8.9 & 2.0 & 1.64 & .56 & 181.6 & 21 & 382.6 & 15 \\
\hline Ventromedial Septal Lesions & 17 & $3.9 *$ & 1.0 & $.48^{*}$ & .11 & $387 * *$ & 28 & 364.0 & 13 \\
\hline \multicolumn{10}{|c|}{ B. Subdivisions of the 17 Lesioned Rats $\dagger$} \\
\hline Dorsal & 12 & 2.4 & .7 & .31 & .12 & 379.0 & 36 & 365.6 & 14 \\
\hline Ventral & 5 & $7.4^{*}$ & 2.5 & $.87 *$ & .17 & 407.6 & 43 & 360.2 & 31 \\
\hline
\end{tabular}

*Differs significantly from the group above it in the table, $p<.05$ (two tailed). $p<.001$ (two tailed). TSee text for explanation.

sitivity, and the subsequent interference with escape performance (learned helplessness) are also reduced or eliminated by ventromedial septal lesions (Kelsey, 1975; Kelsey \& Baker, 1983). The finding that a variety of physiological and behavioral responses to the stress of inescapable shock are reduced by ventromedial septal lesions indicates that these different effects are all mediated, in part, by fibers synapsing in or passing through the ventromedial septum and that they may all share a similar physiological substrate.

Ventromedial septal lesions could reduce gastric erosions by directly interfering with the peripheral, physiological mechanisms mediating the erosion process. For example, since corticosterone secretion has been correlated with the extent of gastric erosions (Weiss, 1971), ventromedial septal lesions could reduce stomach erosions because they reduce corticosterone secretion (Kelsey, 1975). However, the finding that elimination of corticosterone secretion by adrenalectomy does not reduce and occasionally enhances stress-induced gastric erosions (e.g., Brodie \& Hanson, 1960; Djahanguiri, Taubin, \& Landsberg, 1973) indicates that this possibility is unlikely. Although septal lesions can alter autonomic nervous system function (e.g., Holdstock, 1970), I have found no reports that these lesions affect the processes most often implicated in gastric erosionsgastric acid secretion, mucosal blood flow, and mucous secretion (e.g., Djahanguiri et al., 1973; Levine \& Senay, 1970). Moreover, the selective disruption of specific peripheral functions could not account for the effects of ventromedial septal lesions on other responses to inescapable shock.

A more parsimonious explanation is that ventromedial septal lesions reduce all these effects of exposure to inescapable shock because they disrupt a unitary system that is fundamentally involved in mediating responses to inescapable shock. For example, ventromedial septal lesions could reduce these effects by decreasing the painfulness of the inescapable shocks. This particular explanation is untenable, however, because these lesions reduce the analgesia normally produced by inescapable shock, thereby presumably increasing the painfulness of the shocks (Kelsey \& Baker, 1983). A more likely possibility, discussed in detail by Kelsey and Baker (1983), is that these lesions may reduce the ability of rats to learn that the shocks are inescapable or that they may reduce the aversiveness of such knowledge. Because inescapable shocks usually reduce active responding (e.g., Anisman, deCatanzaro, \& Remington, 1978; Jackson, Maier, \& Rapaport, 1978), such a hypothesis is also consistent with the present finding that rats with ventromedial septal lesions make more crossing responses in the shuttlebox than do the controls during the inescapable shocks.

We have also suggested that ventromedial septal lesions reduce all these responses to inescapable shock because they damage the cholinergic system that projects from the ventromedial septum to the hippocampus via the dorsal fornix and fimbria (Kelsey \& Baker, 1983). This interpretation is consistent with the findings that lesions of the dorsal fornix and fimbria also tend to reduce stomach erosions (Henke, Savoie, \& Callahan, 1981), whereas lesions of the hippocampus or its entorhinal input enhance gastric erosion formation (Henke et al., 1981; Murphy, Wideman, \& Brown, 1979).

The present finding that ventromedial septal lesions reduced both the number and extent (area) of gastric erosion formation is only partially consistent with the finding of Brick et al. (1979) that septal lesions reduced the length, but not number, of gastric erosions produced by $3 \mathrm{~h}$ of cold restraint. Even less consistent with the present finding, Henke (1982) reported that septal lesions failed to alter the number (they did not report length or area) of gastric erosions produced by $24 \mathrm{~h}$ of restraint at room temperature. Some of these differences in outcome may reflect differences in procedure (e.g., inescapable shock vs. restraint) or measurement (area or length vs. number). It is also likely that these differences in outcome reflect differences in lesion size or location. Whereas the lesions in the present study were restricted to the ventromedial septum, the lesions in the studies by Brick et al. and Henke were much larger 
and usually eliminated the entire septal area. Because I found that the most ventral septal lesions extending toward the medial preoptic area appeared to reverse the retarding effects of more dorsal ventromedial lesions, it is possible that larger lesions were less effective in reducing gastric erosions because they extended more ventrally than those of the present study. Because lesions of the dorsolateral septum that spare the ventromedial septum occasionally enhance responses to inescapable shock (Kelsey \& Baker, 1983), it is also possible that large septal lesions failed to consistently reduce gastric erosions because the retarding effect of ventromedial septal damage was offset by the additional dorsolateral septal damage.

Consistent with this interpretation, the histological data provided by Brick et al. (1979) and Henke (1982) indicate that the lesions in Henke's study were larger and more likely to consistently damage both the dorsolateral septum and the most ventromedial septum than were the lesions of Brick et al. Thus, Henke's lesions may have had no effect on gastric erosions because they produced consistent damage to areas that might counteract the effects of ventromedial septal damage. Similarly, the lesions of Brick et al. (1979) may have been more likely to reduce gastric erosions because they less consistently damaged these counteracting areas.

These data are, thus, consistent with the findings that the septal area is complex and consists of several distinct neural systems, some with apparently opposing functions (e.g., Hamilton, Kelsey, \& Grossman, 1970; Kelsey \& Baker, 1983; Swanson \& Cowan, 1979). In particular, these data are consistent with the hypothesis that damage to fibers in the ventromedial septum reduce several responses to the stress of inescapable shocks (Kelsey \& Baker, 1983), including gastric erosion formation.

\section{REFERENCES}

Anisman, H., deCatanzaro, D., \& Remington, G. Escape performance following exposure to inescapable shock: Deficits in motor response maintenance. Journal of Experimental Psychology: Animal Behavior Processes, 1978, 4, 197-218.

Brick, J., Burright, R. G., \& Donovick, P. J. Stress responses of rats with septal lesions. Pharmacology, Biochemistry and Behavior, 1979, 11, 695-700.

Brodie, D. A., \& Hanson, H. M. A study of the factors involved in the production of gastric ulcers by the restraint technique. Gastroenterology, 1960, 38, 353-360.

Djahanguiri, B., Taubin, H. L., \& Landsberg, L. Increased sympathetic activity in the pathogenesis of restraint ulcer in rats. Journal of Pharmacology and Experimental Therapeutics, 1973, 184, 163-168.

Hamilton, L. W., \& Katske, F. A. Rapid gastric ulceration in a modified two-way shuttlebox. Physiological Psychology, 1973, 1, 188-190.

Hamilton, L. W., Kelsey, J. E., \& Grossman, S. P. Variations in behavioral inhibition following different septal lesions in rats. Journal of Comparative and Physiological Psychology, 1970, 70, 79-86.

Henke, P. G. Septal lesions, emotionality, and restraint-induced stomach pathology in rats. Physiology \& Behavior, 1982, 28, 739-741.

Henke, P. G., Savoie, R. J., \& Callahan, B. M. Hippocampal deafferentation and deefferentation and gastric pathology in rats. Brain Research Bulletin, 1981, 7, 395-398.

Holdstock, T. L. Plasticity of autonomic functions in rats with septal lesions. Neuropsychologia, 1970, 8, 147-160.

Jackson, R. L., Maier, S. F., \& RAPAPORT, P. M. Exposure to inescapable shock produces both activity and associative deficits in the rat. Learning and Motivation, 1978, 9, 69-98.

KELSEY, J. E. Role of pituitary-adrenocortical system in mediating avoidance behavior of rats with septal lesions. Journal of Comparative and Physiological Psychology, 1975, 88, 271-280.

Kelsey, J. E., \& BAKER, M. D. Ventromedial septal lesions in rats reduce the effects of inescapable shock on escape performance and analgesia. Behavioral Neuroscience, 1983, 97, 945-961.

Levine, R. J., \& Senay, E. C. Studies on the role of acid in the pathogenesis of experimental stress ulcers. Psychosomatic Medicine, 1970, 32, 61-65.

Murphy, H. M., Wideman, C. H., \& Brown, T. S. Plasma corticosterone levels and ulcer formation in rats with hippocampal lesions. Neuroendocrinology, 1979, 28, 123-130.

Pellegrino, L. J., \& Cushman, A. J. A stereotaxic atlas of the rat brain. New York: Appleton-Century-Crofts, 1967.

Swanson, L. W., \& Cowan, W. M. The connections of the septal region in the rat. Journal of Comparative Neurology, 1979, 186, 621-656.

WEISS, J. M. Effects of coping behavior in different warning signal conditions on stress pathology in rats. Journal of Comparative and Physiological Psychology, 1971, 77, 1-13.

Weiss, J. M. Psychological and behavioral influences on gastrointestinal lesions in animal models. In J. D. Maser \& M. E. P. Seligman (Eds.), Psychopathology: Experimental models. San Francisco: Freeman, 1977.

(Manuscript received July 7, 1983; revision accepted for publication December 7, 1983.) 